\title{
A Research on the Model of Student Loan Repayment Based on a Sinking Fund
}

\author{
Mingfa Zhou, QiongWu, Jinliang Wang, \\ School of Science \\ Jiujiang University \\ Jiujiang, China \\ E-mail: Jiangfengli2000@163.com
}

\begin{abstract}
This paper analyzes the advantages and disadvantages of establishing a debt fund on the repayment of student loan. Based on these analyses, on one hand, we discuss the mode of equal fraction repayment of the total amount of the loan principal and its interest in each term. This mode yields great flexibility in that the repayment fund can have a greater interest rate to enhance the will of the lender to save money in the fund and thus can promote the early repayment. Banks can therefore regulate and control the situation and reduce the rate of contract breaking in loan repayment. Moreover, this mode can work well with the current policy and then can have excellent operability; On the other hand, theoretical analysis and example also shows that if the repayment amounts form a reasonable geometric increasing sequence, the repayment can be even more optimal in that it not only has the advantages of the foregoing mode, but also has the advantage of selecting the increasing rate of payments to adjust the burdens in each period of the repayment and make each period repayment burden relatively equal.
\end{abstract}

Keywords-student loan, repayment mode; repayment fund; burden of repayment

\section{INTRODUCTION}

In recent years, The Chinese Government has enacted many regulations to aid the impoverished undergraduate to complete their studies, such as, "Management Regulations on National Student Loan (for Trial Implementation)" issued by General Office of the State Council enacted in 1999, " Several Policies about Further Performing the National Student Loan " issued by the Ministry of Education, the Ministry of Finance, People's Bank of China and the China Banking Regulatory Commission in 2004, "Interim Regulations on Pay for the National Student Loan and College Tuition" promulgated by the Ministry of Education in 2009, and so on. All these policies document marked that the policies of the National Student Loan have embarked on a track of sound development. Particularly, the pressure on pay and the default risk are significantly reduced by prolonging the deadline of the load, performing the policy of student loan based on the domicile place, and introducing the intermedia such as pay treasure. In addition, all these measurements increase the flexibility of the system of payment and advance the implement of the National Student Loan. However, The current mortgage repayment methods have still used the two systems of average capital plus interest method and average capital method, which imposed too much of a burden on the impoverished graduates at the primary stage of their repayment. It is said that the rate of repayment burden has exceeded the international standard $10 \%$. Many scholars have appealed to adopt a graduated loan repayments that increase monthly in order to increase the flexibility of the repayment for a long time. However, there are no specific solution on this issue. The present paper attempts to address this problem and develops two specific and flexible mode of mortgage repayment.

\section{MODE OF REPAYMENT OF STUDENT LOAN BASED ON A SINKING FUND}

There are three modes of mortgage repayment. (1) repaying the loan at a time, that is, borrowers repay the principal with interest at a time when the loan is due. (2) installment, namely, borrowers repay the principal with interest on the installment. Furthermore, the installment loan can be divided into two forms: equal amount installment payment and variable amount installment payment. In particular, the former can be also divided into two kinds, that is, the decreasing regular payment and the increasing one. The current repayment mode belongs to the decreasing one, since the principal which should be pay by the end of the year is equal but the interest is different. But this mode result in that the rate of individual repayment burden exceeds $10 \%$ at the primary stage of his repayment. Thus, this is not a proper way for the student loan.(3) a repayment mode based on a Sinking Fund, that is, borrowers pay the interest to the lender, meanwhile, and construct a Sinking Fund by saving a fixed amount at every period, in which the accumulated amount just equal to the total amount of the loan at the deadline. The borrowers will pay off the loan at a time( $\mathrm{Li}$ and $\mathrm{Fu}[2])$. Although the first two modes have been used in the National Student Loan, the third one is still not been utilized.

The mode of the Sining Fund is a good basis which benefit us to construct more flexible repayment method. Taking the student loan based on the domicile place as an example, the government can establish a Sinking Fund for every student who borrows from the of National Development Bank, and connects it with student's loan. This fund can only be used to repay the loan and can't be remove or carry the cash. The borrower can stochastically pay to the fund by the " pay treasure" at any time, and check whether the cash has received on the following day in any a bank. We usually assume that the interest rate of the Sining Fund that the bank pay for the borrower is larger than the 
save rate of the corresponding period but less than that of borrowing. Furthermore, the interest is calculated in terms of compounding interests by the bank. The interest on the money is exempt from tax, because recharging cash to the Sinking Fund is repayment behavior associated with his loan. The lending bank will deduct the interest of the loan from the fund account. An default will appear inevitable if the fund account has insufficient cash. The borrower can control the last payment to enable that the accumulated cash in the fund account is not more than the principal of the loan. The loan is payed off when the two amounts is equal to each other.

This repayment mode based on the Sinking Fund has many interesting advantages. Firstly, it enables the borrower more flexible to repay his loan. Then, the lending bank can be benefit from this mode, since it can encourage the borrowers to pay off their loan in advance, and attract more saving. As a result, it improves control method and measures of the lending bank, and benefit reducing the default risk. On the other hand, this mode also lead to more volatile of cash flow of the bank. But the sample are so large that the cash flow of the bank steadily obeys to certain probability distribution, thus the total risk still is controllable and observable. Thus, further study and adjustment are needed for this repayment method.

\section{Mode of Repayment Based on A Sinking Fund with Average CAPITAl Plus Interest Method}

To prevent default when the loan is due, we establish a repayment method which bases on a Sinking Fund with average capital plus interest, which combines the advantages of the repayment mode based on the Sinking Fund and the mode with average capital plus interest, and overcomes the disadvantages of the two modes. Practically speaking, the part of the Sinking Fund of the current mode is corresponding to that of the repayment mode of the student loan mentioned above. That is, the lending bank deducts an amount which is equal to that of average capital plus interest method, if the cash in the fund account is not enough to match the deduction, then a default will takes place. The borrower also can make the cash in the Sinking Fund less than the total amount of the loan by controlling the last payment.

This mode based on the traditional repayment system of average capital plus interest incorporates a Sinking Fund into the model. Because the interest rate of the Sinking Fund is closed to the rate of borrowing, this mode can attract the borrower to save in the account. Therefore, all parties is benefit from this mode. In addition, this repayment method is compatible with the current policy of the National Student Loan, and is implementable in practical, since this mode does not need to change the contract of the loan, and only needs to add a Sinking Fund to the contract. However, this repayment mode can't significantly lower the rate of burden which the borrower bears at the primary stage. Therefore, it also can not significantly reduce the risk of default.
IV

\section{Mode OF RePAyment Based on A Sinking Fund with A PROPORTIONAL INCREMENT}

In order to overcome the deficiency of the mode of repayment based on a Sinking fund with average capital plus interest method, we introduce a modified model in which the payment is deducted in accord to an increment in the proportion.

This repayment model has a remarkable advantage over the model mentioned above. This is because that it can adjust the repayment burden ratio by choosing the ratio of increment of payment amount.

Let the symbol $R \boldsymbol{R} \boldsymbol{R}_{\boldsymbol{k}}$ denote the repayment burden ratio, then

$$
R B R_{k}=\frac{\theta_{k}}{s_{k}}, \quad k=1,2, \cdots, n
$$

Where the symbol $\theta_{k}$ is the amount which the borrower should pay to the lending bank, being the annual income of the graduate in the k.th year. Assume that the growth of his annual income is $r$, and the starting payment is $S_{1}$, then

$$
s_{k}=s_{1}(1+r)^{k-1}, \quad k=1,2, \cdots, n,
$$

In addition, supposing the principal of loan being $L$, the interest rate $i$, the term of the loan $n$. The lending bank deducts the payment from the Sinking Fund once a year. Thus, the payment $\theta_{k}$

should be rewrote as

$$
\theta_{k}=\theta_{1}(1+j)^{k-1}, \quad i=1,2, \cdots, n
$$

where $j$ denotes a proportion of increase of $\theta_{k}$. As a result,

$$
R B R_{\mathrm{k}}=R B R_{1}\left(\frac{1+j}{1+r}\right)^{k-1}, \quad i=1,2, \cdots, n
$$

However, we have

$$
\begin{aligned}
& \begin{aligned}
L & =\frac{\theta_{1}}{1+i}+\frac{\theta_{2}}{(1+i)^{2}}+\ldots \ldots+\frac{\theta_{n}}{(1+i)^{n}} \\
& =\frac{\theta_{1}}{1+i}+\frac{\theta_{1}(1+j)}{(1+i)^{2}}+\ldots \ldots+\frac{\theta_{1}(1+j)^{n-1}}{(1+i)^{n}} \\
& =\frac{\theta_{1}}{i-j}\left[1-\left(\frac{1+j}{1+i}\right)^{n}\right]
\end{aligned} \\
& \text { Therefore, } \quad \theta_{1}=L(i-j) /\left[1-\left(\frac{1+j}{1+i}\right)^{n}\right]
\end{aligned}
$$

It is obvious that the repayment burden ratio $R B R_{k}$ is increasing when $j>r$; being decreasing when $j<r$; $R B R_{k}$ being a constant when $j=r$. An ideal case is that $R B R_{k}$ is a constant, which shows that the repayment burden ratio is steady. But it is impossible to make $i$ equal to $j$, since the increasing speed of income of every period in the future is stochastic. We can demonstrate that the variance of repayment burden 
ratio will be decrease under some proper conditions, if $j$ is quite close to $r$. Thus, the borrower will bear a equilibrium pressure of payment.

Therefore, we can adjust the repayment burden ratio to make it more steady relatively by taking the optimal proportion $j$ of increasing.
To illustrate our model, we consider a following specific example. Let the total amount of loan $L$ equal to 24000 , the annual rate of $7.05 \%$. Assuming the term of the loan being 10 years, and the starting payment $s_{1}=28161$. Table 1 lists all result of calculating.

TABLE I. THE REPAYMENT BURDEN RATIO WITH $r=5 \%$ AND $j=5 \%$ AND WITHOUT A GRACE PERIOD

\begin{tabular}{|c|c|c|c|c|c|c|c|c|c|c|}
\hline years & 1 & 2 & 3 & 4 & 5 & 6 & 7 & 8 & 9 & 10 \\
\hline $\begin{array}{c}\text { income } \\
\text { deduction } \\
1\end{array}$ & 3424.96 & 3424.96 & $\begin{array}{c}3424.9 \\
6\end{array}$ & 3424.96 & 3424.96 & 3424.96 & 3424.96 & 3424.96 & 3424.96 & 3424.96 \\
\hline $\boldsymbol{R B R _ { k }}$ & 0.12162 & 0.11583 & $\begin{array}{c}0.1145 \\
5\end{array}$ & 0.10506 & 0.10006 & 0.09530 & 0.09076 & 0.08643 & 0.08230 & 0.07840 \\
\hline $\begin{array}{c}\text { deduction } \\
2\end{array}$ & 2798.44 & 2938.37 & $\begin{array}{c}3085.2 \\
8\end{array}$ & 3239.55 & 3401.53 & 3571.60 & 3750.18 & 3937.69 & 4134.58 & 4341.30 \\
\hline \begin{tabular}{c} 
RBR $_{k}$ \\
\hline
\end{tabular} & 0.09938 & 0.09938 & $\begin{array}{c}0.0993 \\
8\end{array}$ & 0.09938 & 0.09938 & 0.09938 & 0.09938 & 0.09938 & 0.09938 & 0.09938 \\
\hline
\end{tabular}

Where the mode of deduction 1 present the repayment method of average capital plus interest, the deduction2 expresses the repayment method of proportional increment.Table1 shows that according to the deducting mode 1 , all the repayment burden ratio $R B R_{k}$ in the first five year exceed the international standard $10 \%$, therefore, the borrower bear greater pressure at the primary stage of the repayment, but the pressure will lower at the later periods. However, using the deducting mode $2, R B R_{k}$ always is a constant and less than $10 \%$, this illustrates the pressure of repayment is steady.

TABLE II. THE REPAYMENT BURDEN RATIO WITH $r=5 \%$ AND $j=5 \%$ ANDA GRACE PERIOD OF TWO YEARS

\begin{tabular}{|c|c|c|c|c|c|c|c|c|c|c|}
\hline year & 1 & 2 & 3 & 4 & 5 & 6 & 7 & 8 & 9 & 10 \\
\hline income & 28161 & 29569 & 31047 & 32600 & 34230 & 35941 & 37738 & 39625 & 41607 & 43687 \\
\hline $\begin{array}{c}\text { deduction } \\
1\end{array}$ & 1692 & 1692 & 3713.32 & 3713.32 & 3713.32 & 3713.32 & 3713.32 & 3713.32 & 3713.32 & 3713.32 \\
\hline $\boldsymbol{R B} \boldsymbol{R}_{k}$ & $\begin{array}{c}0.060 \\
08\end{array}$ & $\begin{array}{c}0.0572 \\
2\end{array}$ & 0.11960 & 0.11390 & 0.10848 & 0.10332 & 0.09839 & 0.09371 & 0.08925 & 0.08500 \\
\hline $\begin{array}{c}\text { deduction } \\
2\end{array}$ & 1692 & 1692 & 3432.99 & 3604.64 & 3784.87 & 3974.12 & 4172.82 & 4381.46 & 4600.53 & 4830.56 \\
\hline$R_{B} R_{k}$ & $\begin{array}{c}0.060 \\
08\end{array}$ & $\begin{array}{c}0.0572 \\
2\end{array}$ & 0.11057 & 0.11057 & 0.11057 & 0.11057 & 0.11057 & 0.11057 & 0.11057 & 0.11057 \\
\hline
\end{tabular}

From Table2, we know that with a grace period, adopting the mode of deduction 1 will similarly make the borrower bear a greater pressure which is larger than $10 \%$ at the primary stage of repayment, while the deduction 2 will enable the borrower to undertake a greater burden at the later period,. These data show that using a grace period is improper when the increment speed $r$ of the annual income.

TABLE III. THE REPAYMENT BURDEN RATIO WITH $r=8 \%$ AND $j=8 \%$ AND WITHOUT A GRACE PERIOD

\begin{tabular}{|c|c|c|c|c|c|c|c|c|c|c|}
\hline year & 1 & 2 & 3 & 4 & 5 & 6 & 7 & 8 & 9 & 10 \\
\hline income & 28161 & 30414 & 32847 & 35475 & 38313 & 41378 & 44688 & 48263 & 52124 & 56294 \\
\hline $\begin{array}{c}\text { deduction } \\
1\end{array}$ & $\begin{array}{c}3424 . \\
96\end{array}$ & 3424.96 & 3424.96 & 3424.96 & 3424.96 & 3424.96 & 3424.96 & 3424.96 & 3424.96 & 3424.96 \\
\hline $\boldsymbol{R B} \boldsymbol{R}_{k}$ & $\begin{array}{c}0.121 \\
62\end{array}$ & 0.11261 & 0.10247 & 0.09655 & 0.08939 & 0.08277 & 0.07664 & 0.07096 & 0.06571 & 0.06084 \\
\hline $\begin{array}{c}\text { deduction } \\
2\end{array}$ & $\begin{array}{c}2468 \\
26\end{array}$ & 2665.72 & 2878.99 & 3109.30 & 3358.04 & 3626.68 & 3916.82 & 4230.16 & 4568.58 & 4934.06 \\
\hline $\boldsymbol{R} \boldsymbol{B} \boldsymbol{R}_{k}$ & $\begin{array}{c}0.087 \\
65\end{array}$ & 0.08765 & 0.08765 & 0.08765 & 0.08765 & 0.08765 & 0.08765 & 0.08765 & 0.08765 & 0.08765 \\
\hline
\end{tabular}


When the borrower's growth of annual income is at a higher level, comparing Table1 and Table 2, we have a similar finding. Using the deduction1, at the initial stage, namely, all $R B R_{1}, R B R_{2}$ and $R B R_{3}$ will beyond $10 \%$, while at Table1, there exist five year in which $R B R_{\mathrm{k}}$ is larger than $10 \%$. For the deduciton2, the balanced repayment burden ratio $R B R_{k}$ is 0.08765 , which is less than that 0.09938 of Table1.

TABLE IV. THE REPAYMENT BURDEN RATIO WITH $r=8 \%$ AND $j=8 \%$ ANDA GRACE PERIOD OF TWO YEARS

\begin{tabular}{|c|c|c|c|c|c|c|c|c|c|c|}
\hline year & 1 & 2 & 3 & 4 & 5 & 6 & 7 & 8 & 9 & 10 \\
\hline $\begin{array}{c}\text { income } \\
\text { deduction } \\
1\end{array}$ & 1692 & 1692 & 3713.32 & 3713.32 & 3713.32 & 3713.32 & 3713.32 & 3713.32 & 3713.32 & 3713.32 \\
\hline$R B R_{k}$ & $\begin{array}{c}0.06 \\
008\end{array}$ & 0.05563 & 0.11305 & 0.10467 & 0.09692 & 0.08974 & 0.08309 & 0.07694 & 0.07124 & 0.06596 \\
\hline $\begin{array}{c}\text { deduction } \\
2\end{array}$ & 1692 & 1692 & 3113.07 & 3362.12 & 3631.08 & 3921.57 & 4235.30 & 4574.12 & 4940.05 & 5335.25 \\
\hline$R B R_{k}$ & $\begin{array}{c}0.06 \\
008\end{array}$ & 0.05563 & 0.09477 & 0.09477 & 0.09477 & 0.09477 & 0.09477 & 0.09477 & 0.09477 & 0.09477 \\
\hline
\end{tabular}

When considering the first type of deduction, Table4 tell us that only $R B R_{3}$ and $R B R_{4}$ exceed $10 \%$, there have low repayment burden ratio at all other periods.As far as the deduction 2 is concerned, with a grace period, the balanced $R B R_{k}$ is less than $10 \%$, these observations imply that with a higher growth of annual income, the model 2 is proper approach to deduct from the Sinking Fund.

\section{CONCLUSION}

This paper constructs a new model of repayment based on a Sinking Fund. This mode provides the borrower with a flexible method of repayment. In addition, the mode can attract the borrowers to repay their loan actively, because the Sinking Fund not only has higher interest rate than that of saving, but also is free-tax. As a result, it reduces the default risk which the lending bank may incur. Finally, this mode is compatible with the current policies of the Student Loan and implementable in practical. All in all, the mode of repayment introduced in this paper has important academic implication and applicable value.

\section{ACKNOWLEDGMENT}

We are grateful to all anonymous referees. We would like to thank the financial support of Humanity and Social Science of Ministry of Education of China(Grant11YJA790224). Of course, we are responsible for any remaining shortcoming.

\section{REFERENCES}

[1] Hua. Shen and Hong.Shen." A research on the repayment burden ratio and the comparison among different country ", Comparative education research, vol.10, 2004, pp123-127

[2] X. Li and A. Fu. "Actuarialresearch", Beijing: China Renmin University Press, 2002

[3] Ziderman, Adrian, "The Student Loan Scheme in Thailand: A Review and Recommendations for Efficient and Equitable Functioning of the Scheme $\{\mathrm{P}\}$ ” . UNESC0-Bangkok, TA2996THA. 1999. 